\title{
Efficiency Losses in Healthcare Organizations Caused by Lack of Interpersonal Relationships
}

\author{
Perdas de Eficiência em Organizações de Saúde Causadas pela Falta de \\ Relacionamentos Interpessoais
}

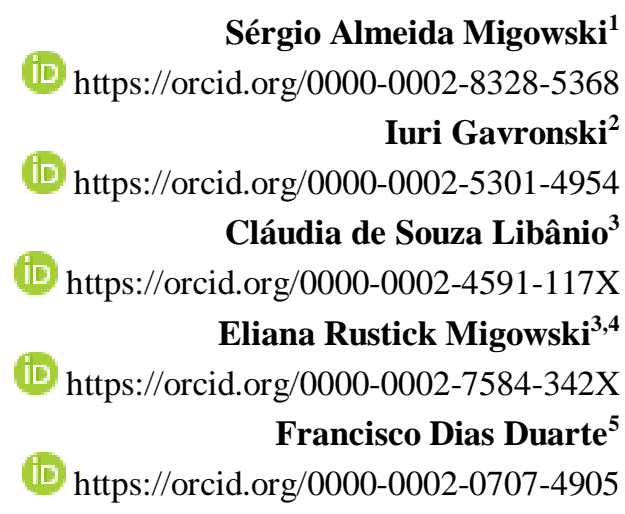

Instituto Federal de Educação Ciência e Tecnologia do Rio Grande do Sul, Gestão e Negócios, Canoas, RS, Brasil ${ }^{1}$ Universidade do Vale do Rio dos Sinos, Programa de Pós-graduação em Administração, Porto Alegre, RS, Brasil ${ }^{2}$ Universidade Federal de Ciências da Saúde de Porto Alegre, Programa de Pós-graduação em Tecnologia da Informação e Gestão em Saúde, Porto Alegre, RS, Brasil ${ }^{3}$ Universidade Feevale e Faculdade de Desenvolvimento do Rio Grande do Sul, Escola de Enfermagem, Porto Alegre, RS, Brasil ${ }^{4}$

Pontifícia Universidade Católica do Rio Grande do Sul, Faculdade de Biociências, Porto Alegre, RS, Brasil ${ }^{5}$ 


\title{
Resumo
}

Apesar das prescrições da literatura sobre gestão da qualidade e integração para implementar estratégias que melhorem o desempenho organizacional, as organizações de saúde sustentam um modelo que é ineficiente, caro e insustentável ao longo do tempo. Este estudo objetiva examinar os relacionamentos interpessoais em três hospitais de grande porte localizados no sul do Brasil e sua relação com a eficiência organizacional. Através de uma pesquisa qualitativa e explicativa, entrevistas semiestruturadas foram aplicadas em 32 profissionais em adição à análise documental. Os dados analisados sugerem que a integração ocorre ao nível das lideranças formais em apenas um dos hospitais e não envolve os profissionais médicos e os operacionais. A gestão da qualidade não parece estar completamente incorporada às rotinas assistenciais e estão relacionadas com perdas de eficiência. Este cenário está provavelmente relacionado com a falta de integração entre os profissionais e da consolidação da confiança, da liderança e da comunicação.

Palavras-chave: gestão da qualidade; eficiência; hospital; relacionamentos interpessoais.

\begin{abstract}
Despite all quality management and integration literature prescriptions to implement strategies for a better organizational performance, healthcare organizations support a model that is inefficient, expensive, and unsustainable over time. This work aims to examine the interpersonal relationships in three large hospitals located in Southern Brazil and its relation with organizational efficiency. Through a qualitative and explanatory research, semi-structured interviews were applied to 32 professionals, in addition to a document analysis. The data analysis shows that integration occurs at the formal leadership level only in one of the organizations and does not involve the medical and operational professionals. Quality management seems not to be fully incorporated into care routines, and are related to efficiency losses. This scenario is probably related to the lack of integration among the professionals and the consolidation of trust, leadership, and communication.
\end{abstract}

Keywords: quality management; efficiency; hospital; interpersonal relationships.

JEL Codes: I11, L14, L15. 


\section{Introduction}

The operations of healthcare organizations are being affected by the increased complexity of the treatments offered to patients and the extremely diverse knowledge of the professionals involved in assistance, which leads to the fragmentation of the services provided. Such fragmentation occurs because each organizational unit is responsible for one of the activities of the health care process (Drupsteen, Vaart, \& Van Donk, 2016). Some authors suggest this model is inefficient, expensive, and unsustainable over time (Smith et al., 2013).

As a way to increase efficiency of the healthcare organizations, defined by Zhang, Fry and Krishnan (2015) as the ability to produce a service with a reduced number of losses, costs, and efforts from the professionals involved, organizational integration has been addressed as an essential element (Bainbridge, Brazil, Ploeg, Krueger, \& Taniguchi, 2016). We define organizational integration as the combination of specialized and differentiated contributions and resources resulting in a multi-party system (cf. Lillrank, 2012).

Integration occurs at the level of professionals and allows organizational members to get access to other areas and understand the key issues of the other ones (Elg, Palmberg, \& Kollberg, 2013). Integration has also been related to the importance of the teamwork for the improvement of quality management (Munechika, Sano, Jin, \& Kajihara, 2014). The quality management prevents information asymmetry and lower results that are reflected in value loss for the patients (Chakraborty \& Dobrzykowski, 2014). Regarded as a systematic process to identify and perform actions able to maintain and improve the quality of care, quality management seeks continuous improvement of the quality of goods and services through the participation of all levels and functions of an organization (Dubey \& Gundsekaram, 2015).

Despite all quality management and integration literature prescriptions to implement strategies for a better organizational performance (Ahire, Golhar \& Waller, 1996; Lillrank, 2012), healthcare organizations seem to face the same problems along the years. Unlike manufacturing firms, there's no way to standardize all the services provided, and it's not possible to collect a sample to test quality. Among the obstacles, are mentioned failures in leadership and communication (Wang et al., 2016); organizational culture and lack of support from the top management (Currie \& Harvey, 2000); excessive autonomy given to the physician, which distances him/her from the other professionals (Rafter et al., 2015); and lack of cooperation among the professionals involved (Contandriopoulos et al., 2015).

Due to the relevance of operations of healthcare organizations, as our first contribution to literature, we argue that is necessary to focus on interpersonal relationships as a strategic tool to consolidate quality management. In fact, Kaynak and Hartley (2008) confirmed a strong relation between employee relations to improve quality management through training and customer focus.

In order to make quality management practiced by all professionals, we argue as a second contribution that interpersonal relationships take place through leadership, communication, and trust. The leaderships must be committed, and all those involved in the processes of social assistance must participate (Lagrosen, Bäckström, \& Wiklund, 2012). Such involvement is reflected in the quality of communication between them (Tibbs \& Moss, 2014), as well as the necessary trust to delegate authority to the subordinates (Yoon, Kim, \& Shin, 2016), which increases the commitment and productivity, resulting in a better and more efficient assistance (Kærnested \& Bragadottir, 2012). As well, we hope to contribute to a deeper understanding of each of the elements necessary for the quality management.

Thus, given the importance of interpersonal relationships among the professionals involved in quality management, the purpose of this study is to examine the interpersonal relationships in three large hospitals in Brazil and its relation with organizational efficiency. As well, we hope to contribute to a deeper understanding of each of the elements necessary for the quality management. In the following sections, the main concepts of service operations management and the central concepts of integration, 
efficiency, quality management, and interpersonal relationships (communication, leadership, and trust) are presented.

\section{Theoretical Foundation}

\section{Management of service operations}

The studies on service operations management are necessary due to the high variability in the production of services. In general, they are provided by different individuals with the possible participation of the customer in the production, which makes them difficult to be standardized and enables the occurrence of errors, with them being realized or not perceived by the customers (Metters \& Marucheck, 2007).

Among the service operations that have expanded its complexity is the operations of healthcare organizations (Mahdavi, Malmström, Van de Klundert, Elkhuizen, \& Vissers, 2013). Considered as complex organizations, hospitals have to deal with the unpredictability, the uncertainty, and a great variety of actors dealing with situations that requires improvisational behavior. Besides this, some of them as physicians have professional autonomy, which means a power sharing with hospital managers (Etzioni, 1964, McDaniel, 2007; Pascucci \& Meyer, 2013). In this sector, two factors have been crucial when seeking for improved efficiency: the rapid growth of costs; and the expressive growth of users for a quality service (Ahmadi-Javid, Jalali, \& Klassen, 2017).

The quality of the processes experienced by patients during the assistance received is a vital component to the organization's performance (Ponsignon, Smart, Williams, \& Hall, 2015). As the services are provided by humans for humans, the support given by the immediate supervision and the establishment of a working environment, where failures can be discussed openly, are instrumental for improving the efficiency and the quality of the services provided (Tucker, 2007).

\section{Efficiency}

Factors such as excessive workload, lack of visibility of processes and variability/uncertainty of this segment are obstacles to the integration and efficiency reduction (Parnaby \& Towill, 2008). Most of these variabilities/uncertainties have internal causes (Böhme, Williams, Childerhouse, Deakins, \& Towill, 2014), causing the need for task-forces to reduce them. But they must count on the top management support (Curry et al., 2015; Parnaby \& Towill, 2008).

Unlike manufacturing, in which interchangeable parts and exact measurements can be put together, in the service delivery in the health area, several elements can not be standardized (Lillrank, 2012). Although protocols exist and are useful in decision making, the variability in each process is related not only to the peculiarities of each patient (chronic diseases, lifestyle, genetic inheritance) but also to the subjectivity of each professional involved in the process, which is reflected in the data interpretation (Taylor, 2014). Besides, as hospitals are complex organizations, many decisions are taken by the staff involved with the patients which means that managers should prepare them to improve organizational performance instead of offering decisions based on forecasts (McDaniel, 2007).

When it comes to efficiency indicators, some authors point the relationship between increased hospital costs and the increased average length of stay due to the associated infections that have been carried out for some years (Schmidt, Geisler, \& Spreckelsen, 2013). The average stay rate enables checking for efficiency in all processes involving the patient. It is related to increased costs (Titler et al., 2008); quality of process management (Andritsos \& Tang, 2014); errors caused during the bed hygiene or while care professionals provide services (Agarwal, Sands, \& Schneider, 2010); and generation of income due to flow improvement (New, McDougall, \& Scroggie, 2016). 
Planning the patient's discharge is another process which can be investigated as an indicator of efficiency. Given the fragmentation of the assistance given and the possibility of iatrogenic diseases that a longer stay may cause to the patient, the discharge planning results from the integration between the various professionals who collaboratively interact to provide a patient-centered assistance (Rhodes, 2013). Iatrogenic diseases or events are those covering property damage (for example: use of medicines, unnecessary surgeries, mutilation) and psychological damage (psycho-iatrogeny-behavior, attitudes, words) caused to the patient not only by a doctor but also by other professionals involved (Paruch, Ko, \& Bilimoria, 2014).

\section{Integration}

One of the greatest challenges faced by the organizations is to enable the integration to occur and to overcome the many individual interests which includes the excess of autonomy of the physicians that distances them from other professionals (Rafter et al., 2015). Therefore, leaders must be able to persuade other professionals that the objective will only be achieved if there is willing to be part of groups and these must interact among themselves. They must understand that the long-term benefits will be higher than the immediate gains, to the extent they try to maintain the social relationships (Hakonsson, Obel, Eskildsen, \& Burton, 2016).

In fact, organizations are under a dualism since they are made up of formal and informal structures of control. While the formal organization is composed of a set of rules, processes and coordination structures, and control of activities, the informal organization results from individual behaviors and several interactions between individuals. There are other norms, values, and beliefs guiding the behavior and the interactions. Objectively, one can not say that there is an optimal configuration for formal organizational structure, but rather a series of organizational needs that, in the face of external and internal factors, can only be met if there is an integration between formal and informal systems (McEvily, Soda, \& Tortoriello, 2014) and between the managers in the strategic level and in the operational level (Kim, Sting, \& Loch, 2014). This means that the integration can occur both at the level of sectors and through the participation of professionals who work with integration. However, at the professional level, this integration is most likely to occur if the professionals clearly understand their individual goals and that, through collective effort, they will be more easily achieved (Haley, 2012).

\section{Quality management}

The quality management in health care organizations has two important dimensions: one that meets the professional requirements and another that meets the expectations of patients and society. Meeting the professional requirements means that they meet pre-established specification, which includes indicators such as mortality and associated infections. Meeting the expectations of patients is related to achieving their recovery, with the least amount possible of adverse effects, and that their healing is quick in case of surgical intervention (Manjunath, 2008). Both dimensions, when effective, generate the result of the quality management which is the quality itself that requires dedication and attention to details (Kuei \& Lu, 2013). Hence, an organization's output is only as good as its inputs which means any fail can provoke unexpected events in the process that can compromise an organization's ability to produce with quality (Zu \& Kaynak, 2012).

The difficulty in defining objectively the quality in healthcare organizations is linked to the characteristics of the services provided. It depends not only on the assistential processes, but also on the individual characteristics of the patient and of those who provide assistance, including their skill, technical knowledge, and experience (Mosadeghrad, 2013). Basically, quality results from quality management, which requires dedication and attention to details (Kuei \& Lu, 2013).

The search for quality leads to mitigating the errors caused during the assistential processes otherwise iatrogenic events may occur (Barbosa, Oliveira, Lopes, Poletti, \& Beccaria, 2014), and the most common mistake involves the administration of drugs, since it is an activity that occupies $40 \%$ of the working time of nursing professionals (Kavanagh, 2017). This is where the quality management works 
through the culture of patient safety. It helps to reduce and prevent mistakes and to reverse and minimize the potential adverse effects of a wrong medication. It can be defined as a set of behavioral patterns of individuals and groups who, based on their values and attitudes, determine how they will exercise their work. That culture includes good communication, leadership, and mutual trust in relation to the measures adopted and practiced by all (Vincent, 2009). By preventing to search for and punish those that are guilty, the professional is encouraged to notify the error as soon as possible so that corrective actions are made, thus enabling the identification of the causes for the mistake to be made (Wright, 2013).

Therefore, practices such as punishment and dismissal should be avoided (Haw, Stubbs, \& Dickens, 2014). In addition to not stimulating spontaneous notifications, they double punish the professional who, when recognizes his/her mistake, starts to feel so guilty that is strongly and emotionally affected (Ullström, Sachs, Hansson, Øvretveit, \& Brommels, 2014). If the human errors can lead to serious complications to patients, to healthcare organizations, they generate not only financial losses that are in general difficult to be measured (Tucker, 2004), but also efficiency losses due to extending the length of stay (Quaglini, 2010).

Another focus of quality management is the associated infections. Lo, Lee, Chen and Liu (2014) emphasize that the associated infections occur in patients hospitalized for 48 hours or more. Rahmqvist, Samuelsson, Bastami and Rutberg (2016) showed that the longer average length of stay caused by associated infections accounts for $11.4 \%$ of the total hospital costs.

At least $30 \%$ of all patients admitted to Intensive Care Units (ICUs), because of their low immunity, will have some type of associated infection (Alp \& Damani, 2015). Approximately 1.7 million associated infections are estimated to occur per year in the United States and are related with 99,000 annual deaths to a cost estimated in U\$9.8 billion (Pina, Ferreira, Marques, \& Matos, 2010). Some factors are related to such high values: lack of knowledge about rates, lack of commitment from the leaderships, and lack of understanding of the importance of the correct techniques about hand hygiene (Taylor, 2014). Among the main prevention and control measures are the fulfillment of good practices, such as basic precautions (hand hygiene, proper use of personal protective equipment, environmental control) and isolation, the rational use of antimicrobials (antibiotics) (Pina et al., 2010) and the elimination or reduction of the use of catheters (Calderon, Kavanagh, \& Rice, 2015).

This last practice created another indicator, the rate of primary bloodstream infection associated with the central venous catheter (CVC). CVC is a frequent procedure in any ICU since it enables hemodynamic monitoring, maintenance of a solution and medication infusion pathway, parenteral nutrition, hemodialysis, and collection of blood samples (Akmal, Hasan, \& Mariam, 2007). According to the most recent epidemiological data, in 2014, CVC corresponded to 5.1 infections per 1,000 CVC/day (Agência Nacional de Vigilância Sanitária, 2015), while for ANAHP, it corresponded to 1.89 infections per 1,000 CVC/day (Ribeiro, 2017).

Among the aforementioned measures, hand hygiene has been considered one of the most efficient ways to reduce associated infections (Price et al., 2016), since a 10\% increase in hand-washing indicators is related to a $6 \%$ reduction in associated infections (Sickbert-Bennett et al., 2016). The World Health Organization indicates the diary consumption of alcoholic solution of $20 \mathrm{ml} /$ patient-day for the hygiene (World Health Organization, 2009).

Since the reduction of associated infections is directly related to the collaborative work of all those involved in the various operational processes ( $\mathrm{Su}, 2016$ ), both integration among the professionals and quality management need the interpersonal relationships to be consolidated because of its direct relationship with them.

\section{Interpersonal relationships}

As communication, leadership, and trust are necessary both to the integration among the professionals, enabling a closer relationship between the formal and informal control systems 
(Chakraborty \& Dobrzykowski, 2014, McEvily et al., 2014), and to the quality management, through the culture of patient safety (Vincent, 2009), the following subsections will address these three concepts.

\section{Communication}

Defined as a shared understanding process, which establishes and keeps the relationship between the parts when emerges (Manojlovich, Squires, Davies, \& Graham, 2015), communication has such a relevance in healthcare organizations that has been believed as the main cause of human errors in surgical centers, along with team work (Tibbs \& Moss, 2014) and for 70\% of the damages caused in patients during hospitalization (Leonard, Graham, \& Bonacum, 2004). The quality of communication between physicians and nursing professionals accounts for their satisfaction at work and their degree of commitment (Galletta, Portoghese, Coppola, Finco, \& Campagna, 2016). Thus, creating mechanisms to facilitate the fluidity of information is essential so that the leaders are able to mobilize the ones being led to aim at common objectives, making them feel supported by their superiors, which only occurs when trust is built between the parts (Blidaru \& Blidaru, 2015).

\section{Leadership}

As in other organizations, leadership is regarded as the ability to inspire individual and organizational excellence, creating a shared view for the achievement of organizational objectives (Cliff, 2012). It is not coincidental that some studies associate the existence of a leadership considered reliable that supports the other professionals of the team by reducing falls of patients, pressure ulcers, and associated infections (Vogus \& Sutcliffe, 2007). It is because of the division of responsibilities within a team that the commitment is enhanced and trust between the members is improved (Huesch, 2013).

The environment created by the leadership style determines how team members interact with each other and can stimulate cooperation and genuine motivation among them (Jaramillo, Bande, \& Varela, 2015). It is not something easy to implement since the leader must provide individual support, which may be perceived by those led as respect and concern with their feelings and personal needs (Podsakoff, MacKenzie, Moorman, \& Fetter, 1990). And in healthcare organizations, the quality of work environments significantly impacts the assistential care because it is reflected in the quality of communication and trust among the members of a team (Plasse, 2017).

\section{Trust}

The concept of trust in healthcare organizations involves a delegation that is effective and able to increase their job satisfaction, productivity, and cooperation among team members (Yoon et al., 2016). Trust is closely linked to patient safety, because it is through it that the professional is encouraged to notify her/his mistakes, allowing the identification of the causes, reducing the adverse events with patients, and avoiding increased costs (Wright, 2013).

In complex environments as these, trust is a key component since assistance is provided by several professionals, but with interdependent functions. It is also through a mutual trust that authority to others is delegated, so that they make decisions when a leader is absent (Yoon et al., 2016). On the other hand, when the many sectors of the healthcare organizations seem to work as hermetic silos that become barriers to building trust and integration, making each individual seeks only what is good for his/her own sector (Weller, Boyd, \& Cumin, 2014).

Study of Vogus and Sutcliffe (2007) showed that trust among nursing professionals and their leaders enhanced patient safety by reducing drug errors. In environments pervaded by trust, the nursing professionals felt comfortable discussing security protocols as well as proposing routines that were not considered safe, which was reflected in the quality management. 


\section{Theoretical framework proposal}

In this study, it is proposed that the integration between the professionals, the quality management in interpersonal relationships, represented by leadership, communication, and trust, may affect the improvement of efficiency in healthcare organizations. In order to make this a commitment from all, the professionals who effectively make the daily decisions and operationalize the care must be integrated into building and improving the processes (Yee et al., 2015). As the greatest resistance to this model may emerge from formal leaderships, they must be developed so that they understand that the decisions made in their sectors create systemic reflections, including in the professionals who work in that particular sector. As they start to communicate with all sectors and professionals, they realize that sharing information and granting autonomy reduces their workload, allowing them to have more time to coordinate the various resources (Bisel, Messersmith, \& Kelley, 2012).

This new leadership profile ends up promoting the establishment of an environment pervaded by trust, in which errors are handled as learning sources and addressed in discussions so that they no longer are repeated. In addition, as the mistakes start to be notified, it is possible to adopt corrective actions in time to reverse any damage caused to the patient (Haw et al., 2014).

Thus, given the integration between the various professionals, the culture of patient safety is now being incorporated. Given this context, as the main theoretical contribution of this study, the theoretical framework was created (Figure 1).

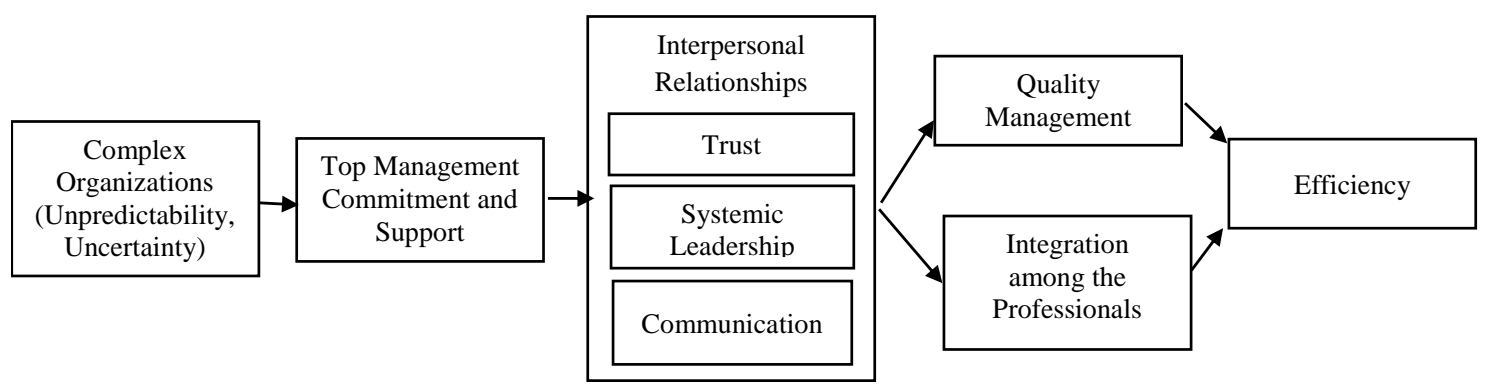

Figure 1. Theoretical Framework: Relationship Among the Central Concepts Source: Created by the authors.

Another potential integration gain among the professionals can arise because of the decisionmaking. Once feeling supported by the others, they will recognize that the decision-making won't have to be made isolatedly and they will do so whenever an adverse event occurs (Morello et al., 2013).

None of this, however, will occur if what is practiced by the top management does not match what they preach. Without a genuine commitment from the top management and a change in the behavior of those managers, the integration aimed will not be achieved, in which sectorization and fragmented assistance will be replaced by collectively developed and sustained processes. They need to circulate over the various units, being interested in the comments made by the operational professionals (Morello et al., 2013).

Thus, when the integration could be perceived by all, the medical professionals will feel encouraged to contribute, as they will understand that the other professionals stopped acting reactively, adopting a proactive position. Otherwise, doctors will keep contributing only when it is interesting for them (Rafter et al., 2015).

With the integration between the professionals being encouraged by the top management and by the other formal leaders, quality management can be implemented because it becomes a commitment of all who understand the importance of their work, so that the culture of patient safety guide all the processes performed. As a result of the integration between professionals and quality management, the efficiency gains are becoming a challenge for all and not just isolated or disconnected actions. The 
maturity of these central concepts occurs when a leader accepts having efficiency losses in their own sector for the benefit of others, whose superior gains will bring benefits to the organization as a whole (Yee et al., 2015).

\section{Methodology}

The research method consists of a multiple case study. The qualitative research enables the researchers to go beyond their initial concepts and review their theoretical frameworks, as it is conducted through an intense and/or prolonged contact with the object (Miles \& Huberman, 1994).

\section{Population and sample}

The limitation in the number of interviews followed the theoretical saturation criterion. Creswell (2010) suggested using 20-30 interviews. In this study, 32 interviews of three large hospitals in Southern Brazil were carried out. Despite the theoretical saturation obtained on the 30th, the two final interviews were maintained. However, new data were not added.

The questions developed were validated by two researchers before being used in the interviews as well by the Presidente of Federação das Santas Casas e Hospitais Beneficentes, Religiosos e Filantrópicos do Rio Grande do Sul who is also director of a large hospital in the state of Rio Grande do Sul. They were carried out along with professionals who have a direct or indirect relationship with the processes analyzed in this study from each of the three selected hospital organizations, in order to identify their perceptions of the relationship between the constructs of interpersonal relationships, safety culture, and its efficiency. The interviews were recorded, transcribed, and conducted between August and December 2016, lasting 30-40 min, resulting in an average of 15 pages per interviewee. The following employees were interviewed: Administrative Manager; Nursing Manager; Clinical Director; Intensivist Physician; Surgeon; Nurse leader of the Adult ICU; Nurse leader of the Adult Hospitalization Unit; Infection Control Coordination; Hospitality Coordination; Hygiene Sector Supervision; and Supervision of the Hospital Bed Center. Interviewees were named as AA, AB, ..., BA, BB, ... and CA, $\mathrm{CB}, \ldots$, according to the hospital to which the interviewees belong. In order to respect their confidentiality, the second letter of the classification is related to interview order.

\section{Procedures and data collection}

The analysis units in the three hospitals were an Adult Intensive Care Unit (AICU) and an Adult Hospitalization Units (HU). Despite of its similar size, the epidemiological profile of each hospital makes it difficult to compare their economic results. Therefore, for the safety culture, it was selected the analysis of the rate related to the incidence of primary bloodstream infection, associated with the central venous catheter (CVC) and the indicator of hand hygiene. As efficiency indicator, the average stay rate was used. Only the rates regarding the AICUs were used because HUs had a high demand of clinical and surgical patients hospitalized simultaneously. As they receive diverse assistance, there are significant differences in average stay and consequently infections with CVC. Both factors could create different bias.

Moreover, some processes were selected for this comparison. Given the complexity and volume of existing processes in both units, we analyzed the processes involving the integration between the assistance professionals, of sanitization, and the processes related to three situations: the hygiene of the bed during and after the hospitalization; and the medical discharge from the unit.

Therefore, there was made the triangulation through semi-structured interviews, document analysis, and analysis of electronic records (Yin, 2015). We compared the three data sources in order to find convergences and divergences and establish the relation of cause and consequence of interpersonal 
relationships on efficiency rates (average stay rate; separation of the clothes according to the degree of dirtiness; sanitization of hospital beds); and quality rates (incidence of primary bloodstream infection associated with the central venous catheter (CVC), reporting of errors, and indicator of hand hygiene).

\section{Data treatment and analysis}

Cluster analysis techniques were used to group expressions found in the reports of external and internal interviewees with a similar meaning. The NVivo software 11 for the decoding. All interviews were read by two researchers making it possible to classify the answers in one of the constructs. Two external researchers assisted in the discussion on how each data should be classified.

After they were inserted into one of the constructs, the selected parts were again read within the NVivo software to check if they were compatible with their meaning, which would mean that they were allocated correctly. Each construct (safety culture, interpersonal relationships, leadership, communication, and trust) was analyzed separately, based on the excerpts of the interviews that were related to each of these concepts. After this, we presented the excerpts for each respondent to validate them (Miles \& Huberman, 1994). At the end of each case study, these concepts were analyzed and compared to the indicators obtained from document analysis, in order to show if there was consistency or discrepancy between the interviews and between these and the documentary data.

\section{Ethical aspects involved when carrying out the research}

This study was authorized by the Research Ethics Committees. By Hospital A, protocol $\mathrm{n}^{\circ}$ 59471316.4.3001.5305; by Hospital B, protocol $\mathrm{n}^{\circ}$ 58900916.4.1001.5335; and by Hospital C, protocol $\mathrm{n}^{\circ}$ 59471316.4.3002.5328. In order to respect their confidentiality, interviewees were named as AA, $\mathrm{AB}, \ldots, \mathrm{BA}, \mathrm{BB}, \ldots$ and $\mathrm{CA}, \mathrm{CB}, \ldots$, according to the hospital to which they belong to. The second letter is related to the order they were interviewed.

\section{Cross-Case Analysis}

This section is dedicated to the presentation of the analysis and the discussion of the data obtained and interviews conducted in the three hospitals used as objects of study. Tables 1 to 6 summarize the obstacles found in the interviews carried out in the three hospitals:

Table 1

Construct - Integration - Barriers

\begin{tabular}{ll}
\hline Construct - Integration - Barriers & Representative Data \\
\hline - Lack of Formal Interaction & "The physician has no corporate relationship with the institution ... if \\
- Physician Autonomy & I don't work here, I'll go somewhere else." (A1) \\
- Sharing of Information & "we stay in the field of performance or creation and it does not get \\
there where it matters, which is at the patient's bedside." (CF) \\
- Organizational Culture & "For them not to feel embarrassed, as they are technicians, we tried \\
- Formal Leadership Style & "according to the leadership of that sector, they will guide the \\
- Informal Leadership Style & $\begin{array}{l}\text { employee to have a good relationship with, to be respectful to other } \\
\text { colleagues." (AA) }\end{array}$ \\
& "when you give autonomy to the decision-making process, it is \\
& $\begin{array}{l}\text { destabilized. The style of the leader and the ones being led influence } \\
\text { this." (CF) }\end{array}$ \\
\hline
\end{tabular}

Note. Created by the authors. 
Table 2

\section{Construct - Quality Management - Barriers}

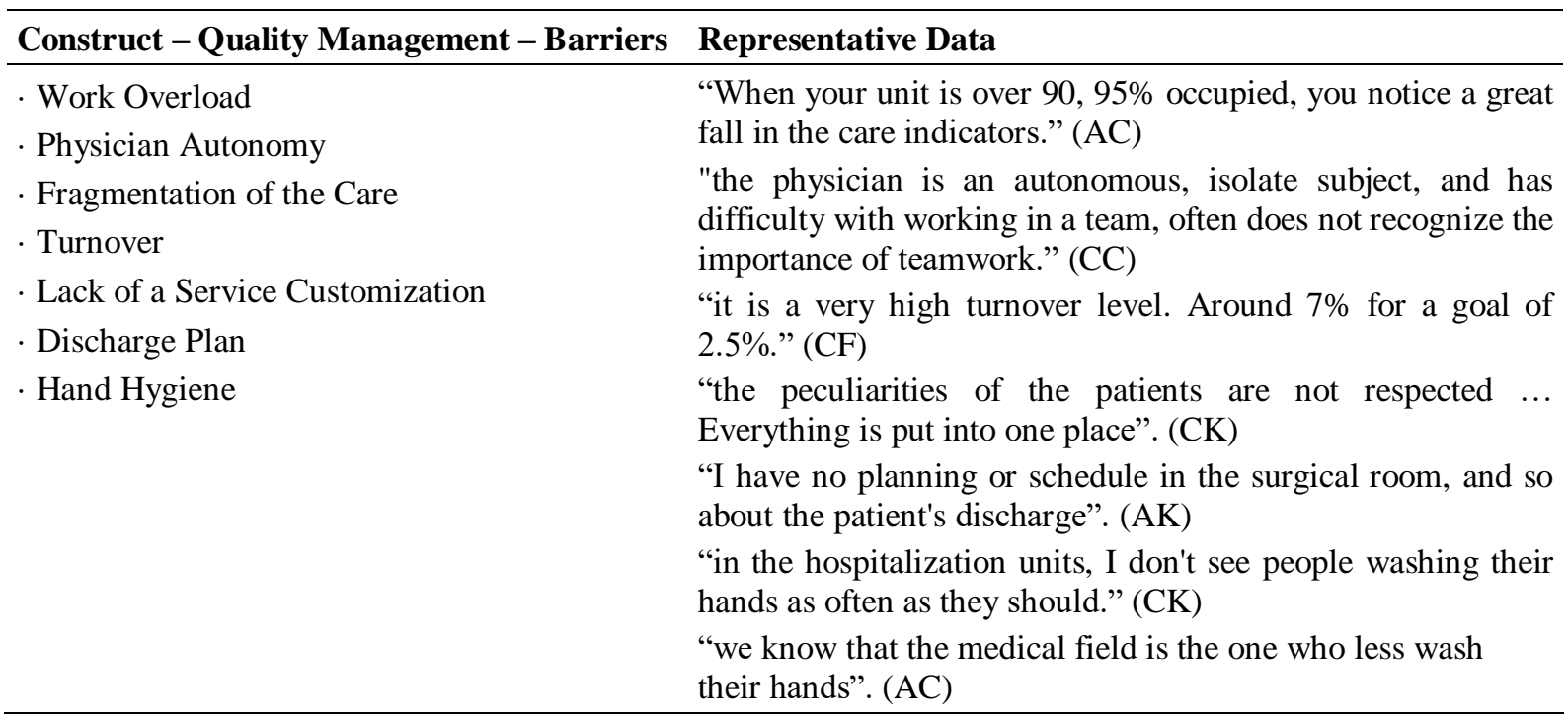

Note. Created by the authors.

Table 3

\section{Construct - Leadership - Barriers}

\begin{tabular}{ll}
\hline Construct - Leadership - Barriers & Representative Data \\
\hline $\begin{array}{l}\text { Participation of the Informal } \\
\text { Leaderships }\end{array}$ & $\begin{array}{l}\text { "sometimes we stay in the field of performance or creation and it does } \\
\text { not get there where it matters, which is at the patient's bedside". (CF) }\end{array}$ \\
" Commitment by Formal Leaderships & $\begin{array}{l}\text { "we need them to buy the idea, and to support it, because if the } \\
\text { leadership does not support anything, nothing moves forward". (CH) } \\
\text { "And then you discover that there were talents hidden until then". (CA) }\end{array}$ \\
\hline
\end{tabular}

Note. Created by the authors.

Table 4

Construct - Communication - Barriers

\begin{tabular}{l}
\hline Construct - Communication - Barriers \\
\hline - Profile of the Formal Leaderships \\
- Distancing Between the Hierarchical \\
Levels \\
- Organizational Culture \\
- Fragile Sharing \\
- Development of the Leaderships
\end{tabular}

Representative Data
"Some nurses are more resistant to passing forward". (CF)
"the employee feels a certain detachment from the board
directors". (BA)
"for example, when the board members walk in, they don't greet
the employees. It makes us look invisible". (BA)
"the other nursing technicians accept better when [the order] comes
from their peers, which is different when it comes from a nurse
because they think the nurse does not know very well their reality".
(CH)
"the staff gets it, but it is not as open as we would like it to be and I
don't think the institution is as open as we imagine it to be either."
(CA)
"and then someday I found out that everybody was using this
syringe, and I never heard of that." (BG)
"there is a surgical room cleaning system that is a communication
through screaming ... whoever shouts louder gets the cleaning staff
to arrive quicker." (CK)

Note. Created by the authors. 
Table 5

\section{Construct - Trust - Barriers}

\begin{tabular}{ll}
\hline Construct - Trust - Barriers & Representative Data \\
\hline Handling the Mistake & "so we learn from our mistakes, but there is also punishment. One thing \\
- Autonomy & "If the mistake was severe or has caused harm to the patient, then I need \\
& to be punished and so does the educational process as well." (CB) \\
& "institutionally there is no punishment, but then you surreptitiously see \\
& the comments, people judging you". (BA) \\
& "in case the individual is not comfortable in exposing the errors made ... \\
& everything is concealed." (CA) \\
"sometimes I can't give so much autonomy, because the individual does \\
not feel prepared". (CF)
\end{tabular}

Note. Created by the authors.

Table 6

\section{Construct - Efficiency - Barriers}

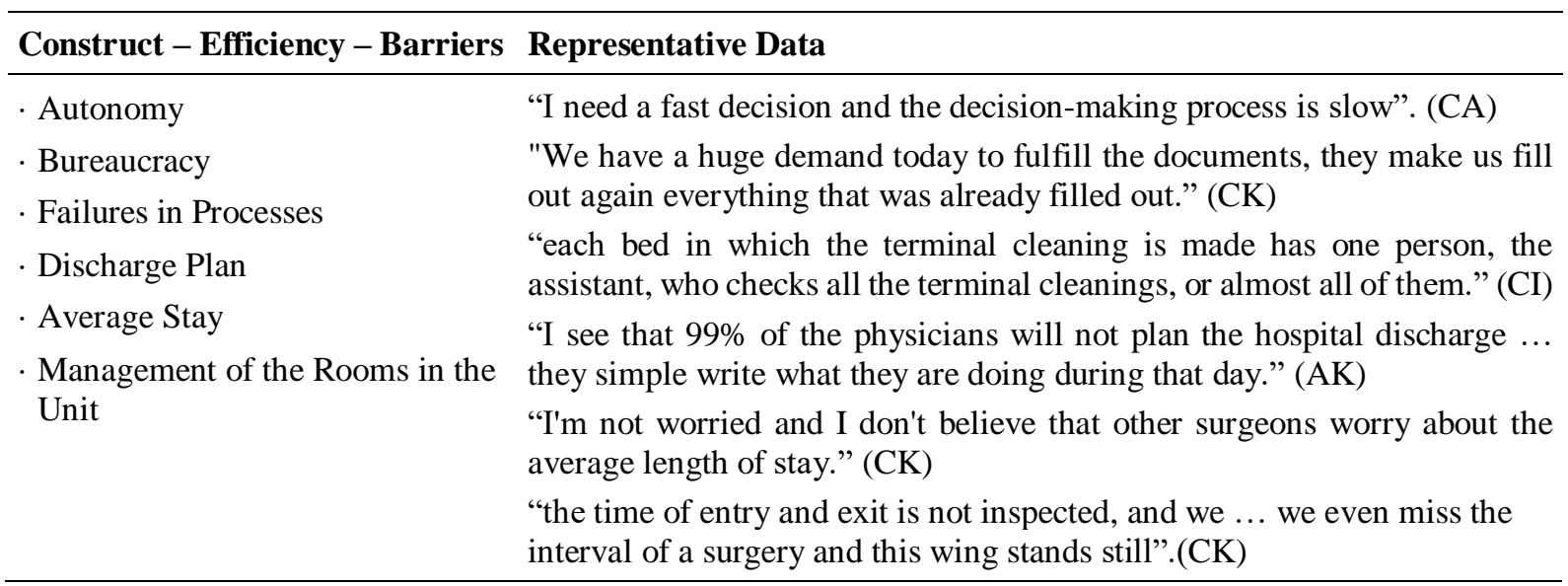

Note. Created by the authors.

Despite the importance of the integration, it does not seem to happen in the sectors of Hospitals A and B. In Hospital C, integration seems to be stronger, but occurs only at the formal leadership level through two rounds per day. They not only make the common definition of the priorities possible, but also checking what was planned. In the three hospitals, the operational level, called by many interviewees as the bedside professional, is excluded from creating the processes, so that much of what is planned ends up not being performed.

Another highlight in the three hospitals is the distance between the top management and the operational professionals. Because they rarely circulate or meet with these professionals, they end up creating a distance and a sense of lack of belonging to and importance of the work they do. The distance between the strategic and the operational levels was said to be an obstacle to the integration by Currie and Harvey (2000) and by Curry et al. (2015). Given the reports, it is seen that the integration takes place only formally in the three hospitals, which does not seem to be a guarantee of success for the existing demands. As trust is not solidly built and supported by the top management through concrete actions and not just speeches, it will be difficult for all involved to be more committed. Thus, the top management must actively participate in the daily life of operational-level professionals (Parnaby \& Towill, 2008). 
The several sectors of the three hospitals analyzed seem to work as hermetic silos that become barriers to building trust and integration (Weller et al., 2014), making each individual seeks only what is good for the sector at which they are working. Thus, the term horizontalization, which is widely used in the interviews, is found only in the field of good intentions.

The main obstacle to building integration seems to be derived from the profile of some formal leaders of the three organizations who do not understand the importance of a systemic view. This means that all the action developed in one sector should be examined also based on the influence caused in other sectors before being implemented. This perception is corroborated by Hakonsson, Obel, Eskildsen, and Burton (2016) who argue for a strong action of the leaderships that could encourage their professionals to create groups interacting with each other. When attempting to maintain social relationships, they stop pursuing short-term gains, adopting actions of collective gain. As each part contributes to the result, they are subject to the demands of the whole (Lillrank, 2012).

Formal leaderships must understand that the competencies of each sector actually derive from individual knowledge and skills of several actors, once they are combined with an integrated coordination. This is why the communication between the coordinations of the services involved in the care provided to the patient, due to the high fragmentation of the care provided, is so important. However, it alone is not enough, as the indicators of Hospital C show that the planned goals were not reached, despite the daily rounds.

As the communication is poor and the professionals who work at the patients' bedside do not participate in the process planning, they may not understand how important it is to perform the task requested as well as to perform it in the best way possible (Bisel et al., 2012). Communication is accounted for the main cause of human mistakes in surgical centers along with the teamwork (Tibbs \& Moss, 2014) and responsible for the satisfaction at work and the degree of commitment of the nursing professionals (Galletta et al., 2016).

For nursing professionals, the degree of autonomy turns out to be reflected on their ability to make decisions and their perception that the results obtained in health care activities are directly related to the degree of effort they put (Galletta et al., 2016). The environment found in the three hospitals does not seem to be that of cooperation or trust. Formal leaders seem to act much more because they feel pressured to do so since they know they will be asked, rather than because they feel motivated to cooperate. This can be seen in several reports.

Several professionals from the three hospitals mentioned the unawareness of innovations of processes implemented in other sectors that end up generating efficiency gains. The lack of sharing suggests that these process improvements are treated as a secret of a particular sector as a way of making gains greater than other sectors. Basically, it is as if a competition for results took place.

Another report points out the need to promote meetings exclusive for nursing technicians when it is desired to multiply improvements or innovations in processes. This strategy is used so that they feel comfortable to expose their points of view without fearing the criticism of their superiors. When used as multipliers, the technicians manage to convince their peers of the need to incorporate the improvements, which may not be possible if this is shared by nurses who ignore the work reality of those professionals. This suggests a distance between two professional categories that should work in an integrated way. In environments pervaded by trust, the nursing professionals feel comfortable to discuss security protocols as well as to improve routines that can mitigate the mistakes (Vogus \& Sutcliffe, 2007).

This context is reflected in the way the mistakes are handled, especially in Hospitals A and C. The reports show that they are handled both as a learning source and as a punishment and that is an institutional practice. In Hospital B, there is the institutional encouragement that the mistake is handled as a learning source, but it is assumed that the colleagues punish the professional who made the mistake in a veiled way. It is true that the mistakes are directly related to the increase in hospital costs due to the increase in the average length of stay. However, it is also true that, as the care is provided by fallible 
human beings and they have flaws, the mistakes are inevitable (Rafter et al., 2015). Therefore, as the mistakes are handled with punishment (institutionally in Hospitals A, B, and C, and not covertly by the peers in Hospital B), the result is that they are undernotified, as the interviewees have themselves admitted. As they don't measure, they are uncapable to put focus on issues that really matter (Elg, Palmberg, \& Kollberg, 2013).

If the integration does not even occur even among the nursing professionals, it can be expected that it will not happen between the medical professionals either. The physicians' autonomy was pointed out by several professionals interviewed, including by the physicians themselves, as a factor that hinders the work of other professionals. It is not by chance that, only in AICUs, the discharge planning is working, also because there is a contractual relationship between this category and the hospital.

The physician's autonomy, pointed out by Rafter et al. (2015) as an obstacle to integration, is also directly related to the quality of the relationships among these medical professionals and the nursing staff. It influences the degree of commitment and reduced intention from the nursing professionals to leave the organization. The turnover, considered as high by Hospitals A and B, is one of the causes of the work overload that appears in the interviews made in the three hospitals. Both work overload and turnover, in turn, are related to the quality management and efficiency of the services provided (Elliott, Young, Brice, Aguiar, \& Kolm, 2014).

Actions in three hospitals that could stimulate the development of the systemic view of formal leaders were not found, leaving the term horizontalization relegated only to the condition of a fad. Also, have not been identified specific actions for the development of informal leaders. In addition to not being involved in the improvement and development of processes, they seem to choose not to have autonomy for fear of being work and being punished.

In the three hospitals, there is a strong presence of teams to revert the CRAs in the HUs. On the other hand, as the bed cleaning after the hospitalization, in all of them, time measurements were not known and their release was more linked to the commitment of each professional than to well-defined processes. In Hospital A, they decided to expand the board of supervisors, as there was no trust in the operational professionals of this sector, which only raised costs without creating a continuous improvement in efficiency

The infection indicator of CVC in the ICU of Hospital A, is at 4.02 infections per 1,000 CVC/day, while its goal in 2016 was of 3.5. In Hospital B, the rate is 4.76 infections per 1,000 CVC/day, against a goal of 3.74. In Hospital A, the rate is at 3.8 infections per 1,000 CVC/day for a goal of 2.2. All the three hospitals have rates lower than those of ANVISA, but higher than those of ANAHP.

Regarding the average length of stay at the AICUs, Hospital A, at the time of the research, had an annual average of 10 days for a goal of 6 days. Hospital B had 11,2 days for a goal of 9 days, and Hospital $\mathrm{C}$ had 7.6 days for a goal of 6 days. In hospitalization units of Hospital C, the average length of stay ranges from 11 and 12 days, while in Hospital B, specifically for SUS patients, the average length is 6.8 days, and in Hospital A, 6.3 days.

\section{Final Considerations}

The difficulties in achieving the efficiency indicators in three healthcare organizations can be originated from the difficulties in performing the quality management. As the several professionals could not be involved in simple actions, such as hand hygiene, the possibility of associated infections is increased, which implies in an increased average length of stay. The inability to achieve improvements in organizational efficiency seems to be the consequence from the lack of integration among the professionals and the consolidation of trust, leadership, and communication. This scenario does not support the theoretical framework proposed, but does not invalidate it. Probably, because it does not 
validate the framework, the efficiency losses still continue to happen, despite the efforts to improve quality management.

As limitations of this study, the lack of economic data that could not be accessed to assist in the comparison of the efficiency of the three healthcare organizations. Finally, this study understands that the work does not end here and, due to its continental dimensions, it would be interesting to replicate this study not only in other units of the Federation, but in other countries as well to check the validity of the theoretical contribution of this study. This paper also expects that the managers can improve their efficiency through the integration of several professionals from different hierarchical levels, as well as consolidate the culture of patient safety as an instrument of quality management.

\section{References}

Agarwal, R., Sands, D. Z., \& Schneider, J. D. (2010). Quantifying the economic impact of communication inefficiencies in U.S. Hospitals. Journal of Healthcare Management, 55(4), $265-$ 281.http://doi.org/10.1097/00115514-201007000-00007

Agência Nacional de Vigilância Sanitária. (2015). Boletim Informativo: Segurança do paciente e qualidade em serviços de saúde $n^{o}$ 11, Ano VI. Recuperado de http://www20.anvisa. gov.br/segurancadopaciente/index.php/publicacoes/item/11-boletim-informativo-seguranca-dopaciente-e-qualidade-em-servicos-de-saude

Ahire, S. L., Golhar, D. Y., \& Waller, M. A. (1996). Development and validation of TQM implementation constructs. Decision sciences, 27(1), 23-56. https://doi.org/10.1111/j.15 40-5915.1996.tb00842.x

Ahmadi-Javid, A., Jalali, Z., \& Klassen, K. J. (2017). Outpatient appointment systems in healthcare: A review of optimization studies. European Journal of Operational Research, 258(1), 3-34. https://doi.org/10.1016/j.ejor.2016.06.064

Akmal, A. H., Hasan, M., \& Mariam, A. (2007). The incidence of complications of central venous catheters at an intensive care unit. Annals of Thoracic Medicine, 2(2), 61-63. https://doi.org/10.4103\%2F1817-1737.32232

Alp, E., \& Damani, N. (2015). Healthcare-associated infections in intensive care units: Epidemiology and infection control in low-to-middle income countries. The Journal of Infection in Developing Countries, 9(10), 1040-1045. https://doi.org/10.3855/jidc.6832

Andritsos, D. A., \& Tang, C. S. (2014). Linking process quality and resource usage: an empirical analysis. Production and Operations Management, 23(12), 2163-2177. https://doi.org/ 10.1111/poms.12249

Bainbridge, D., Brazil, K., Ploeg, J., Krueger, P., \& Taniguchi, A. (2016). Measuring healthcare integration: Operationalization of a framework for a systems evaluation of paliative care structures, process, and outcomes. Paliative Medicine, 30(6), 567-579. https://doi.org /10.1177/0269216315619862

Barbosa, T. P., Oliveira, G. A. A. de, Lopes, M. N. de A., Poletti, N. A. A., \& Beccaria, L. M. (2014). Práticas assistenciais para segurança do paciente em unidade de terapia intensiva. Órgão Oficial de Divulgação Científica da Escola Paulista de Enfermagem da Universidade Federal de São Paulo, 27(3), 243-248. http://doi.org/10.1590/1982-0194201400041

Bisel, R. S., Messersmith, A. S., \& Kelley, K. M. (2012). Supervisor-subordinate communication: Hierarchical mum effect meets organizational learning. The Journal of Business Communication (1973), 49(2), 128-147. 
Blidaru, D. M. A., \& Blidaru, G. R. A. (2015). Organizational communication forms and causes of disruption of organizational communication and their improvement. Valahian Journal of Economic Studies, 6(1), 37-44.

Böhme, T., Williams, S., Childerhouse, P., Deakins, E., \& Towill, D. (2014). Squaring the circle of healthcare supplies. Journal of Health Organization and Management, 28(2), 247-265. https://doi.org/10.1108/JHOM-01-2013-0014

Calderon, L. E., Kavanagh, K. T., \& Rice, M. K. (2015). Questionable validity of the catheter-associated urinary tract infection metric used for value-based purchasing. American Journal of Infection Control, 43(10), 1050-1052. https://doi.org/10.1016/j.ajic.2015.05.024

Chakraborty, S., \& Dobrzykowski, D. D. (2014). Examining value co-creation in healthcare purchasing: A supply chain view. Business: Theory and Practice, 15(2), 179-190. https://doi.org/10.3846/btp.2014.18

Cliff, B. (2012). Patient-centered care: The role of healthcare leadership. Journal of Healthcare Management, 57(6), 381-383. https://doi.org/10.1097/00115514-201211000-00003

Contandriopoulos, D., Brousselle, A., Dubois, C.-A., Perroux, M., Beaulieu, M.-D., Brault, I., Kilpatrick, K., D’Amour, D., Sansgter-Gormley, E. (2015). A process-based framework to guide nurse practitioners integration into primary healthcare teams: Results from a logic analysis. $B M C$ Health Services Research, 15(1), 78. https://doi.org/10.1186/s12913-015-0731-5

Creswell, J. W. W. (2010). Projeto de pesquisa: Métodos qualitativo, quantitativo e misto (2nd ed.). Porto Alegre: Bookman.

Currie, V. L., \& Harvey, G. (2000). The use of care pathways as tools to support the implementation of evidence-based practice. Journal of Interprofessional Care, 14(4), 311-324. http://doi.org/10.1080/13561820020003874

Curry, L. A., Linnander, E. L., Brewster, A. L., Ting, H., Krumholz, H. M., \& Bradley. E. H. (2015). Organizational culture change in U.S. Hospitals: A mixed methods longitudinal intervention study. Implementation $\quad$ Science, $10(29), \quad 1-11 . \quad \mathrm{http}: / /$ doi.org/ 10.1186/s13012-015-0218-0

Drupsteen, J., Vaart, T. van der, \& Van Donk, D. P. (2016). Operational antecedents of integrated patient planning in hospitals. International Journal of Operations \& Production Management, 36(8), 879-900. https://doi.org/10.1108/IJOPM-05-2014-0237

Dubey, R., \& Gunasekaran, A. (2015). Exploring soft TQM dimensions and their impact on firm performance: Some exploratory empirical results. International Journal of Production Research, 53(2), 371-382. http://doi.org/10.1080/00207543.2014.933909

Elg, M., Palmberg, K., \& Kollberg, B. (2013). Performance measurement to drive improvements in healthcare practice. International Journal of Operations \& Production Management, 33(11/12), 1623-1651. https://doi.org/10.1108/IJOPM-07-2010-0208

Elliott, D. J., Young, R. S., Brice, J., Aguiar, R., \& Kolm, P. (2014). Effect of hospitalist workload on the quality and efficiency of care. JAMA Internal Medicine, 174(5), 786-793. http://doi.org/10.1001/jamainternmed.2014.300

Etzioni, A. (1964). Modern organizations. New Jersey: Prentice-Hal.

Galletta, M., Portoghese, I., Coppola, R. C., Finco, G., \& Campagna, M. (2016). Nurses well-being in intensive care units: Study of factors promoting team commitment. British Association of Critical Care Nurses, 21(3), 146-156. https://doi.org/10.1111/nicc.12083 
Hakonsson, D. D., Obel, B., Eskildsen, J. K., \& Burton, R. M. (2016). On cooperative behavior in distributed teams: The influence of organizational design media, richness, social interaction, and interaction adaptation. Frontiers in Psychology, 7(692), 1-11. https://doi.org/10.3389/ fpsyg.2016.00692

Haley, M. D. (2012). Integration: From structural to functional. Healthcare Financial Management, 66(6), 74-77.

Haw, C., Stubbs, J., \& Dickens, G. L. (2014). Barriers to the reporting of medication administration errors and near misses: An interview study of nurses at a psychiatric hospital. Journal of Psychiatric and Mental Health Nursing, 21(9), 797-805. https://doi. org/10.1111/jpm. 12143

Huesch, M. C. (2013). Are there always synergies between productive resources and resource deployment capabilities? Strategic Management Journal, 34(11), 1288-1313. https://doi.org/ $10.1002 / \mathrm{smj} .2068$

Jaramillo, F., Bande, B., \& Varela, J. (2015). Servant leadership and ethics: A dyadic examination of supervisor behaviors and salesperson perception. Journal of Personal Selling \& Sales Management, 35(2), 108-124. http://doi.org/10.1080/08853134.2015.1010539

Kærnested, B., \& Bragadottir, H. (2012). Delegation of registered nurses revisited: Attitudes towards delegation and preparedness to delegate effectively. Nordic Journal of Nursing Research \& Clinical Studies, 32(1), 10-15. https://doi.org/10.1177/010740831203200103

Kavanagh, C. (2017). Medication governance: Preventing errors and promoting patient safety. British Journal of Nursing, 26(3), 159-165. https://doi.org/10.12968/bjon.2017.26.3.159

Kaynak, H., \& Hartley, J. L. (2008). A replication and extension of quality management into the supply chain. Journal of Operations Management, 26(4), 468-489. https://doi.org/10.1016/j.jom.2007.06.002

Kim, Y. H., Sting, F. J., \& Loch, C. H. (2014). Top-down, bottom-up, or both? Toward an integrative perspective on operations strategy formation. Journal of Operations Management, 32(7/8), 462474. https://doi.org/10.1016/j.jom.2014.09.005

Kuei, C., \& Lu, M. H. (2013). Integrating quality management principles into sustainability management. Total Quality Management \& Business Excellence, 24(1/2), 62-78. http://doi.org/10.1080/14783363.2012.669536

Lagrosen, Y., Bäckström, I., \& Wiklund, H. (2012). Approach for measuring health related quality management. The TQM Journal, 24(1), 59-71. https://doi.org/10.1108/17542731211191221

Leonard, M., Graham, S., \& Bonacum, D. (2004). The human factor: The critical importance of effective teamwork and communication in providing safe care. Quality \& Safety in Health Care, 13(Suppl. 1), i85-i90. https://doi.org/10.1136/qshc.2004.010033

Lillrank, P. (2012). Integration and coordination in healthcare: An operations management review. Journal of Integrated Care, 20(1), 6-12. https://doi.org/10.1108/14769011211202247

Lo, Y. S., Lee, W. S., Chen, G. B., \& Liu, C. T. (2014). Improving the work efficiency of healthcareassociated infection surveillance using electronic medical records. Comput Methods Programs Biomed, 117(2), 351-359. https://doi.org/ 10.1016/j.cmpb.2014.07.006

Mahdavi, M., Malmström, T., Klundert, J. van de, Elkhuizen, S., \& Vissers, J. (2013). Generic operational models in health service operations management: A systematic review. SocioEconomic Planning Sciences, 47(4), 271-280. https://doi.org/10.1016/j.seps.2013.07.002 
Manjunath, U. (2008). Core issues in defining healthcare quality. Journal of Services Marketing, 6(4), 72-78.

Manojlovich, M., Squires, J. E., Davies, B., \& Graham, I. D. (2015). Hiding in plain sight: Communication theory in implementation science. Implementation Science, 10(1), 58. https://doi.org/10.1186/s13012-015-0244-y

McDaniel, R. R. (2007). Management strategies for complex adaptive systems sensemaking, learning, and improvisation. Performance Improvement Quarterly, 20(2), 21-41. https://doi.org/10.1111/j.1937-8327.2007.tb00438.x

McEvily, B., Soda, G., \& Tortoriello, M. (2014). More formally: Rediscovering the missing link between formal organizational and informal social structure. The Academy of Management Annals, 18(1), 299-345. http://doi.org/10.1080/19416520.2014.885252

Metters, R., \& Marucheck, A. (2007). Service management—academic issues and scholarly reflections from operations management researchers. Decision Sciences, 38(2), 195-214. http://doi.org/10.1111/j.1540-5915.2007.00156.x

Miles, M. B., \& Huberman, A. M. (1994). Qualitative data analysis (2nd ed.). Thousand Oaks: Sage.

Morello, R. T., Lowthian, J. A., Barker, A. L., McGinnes, R., Dunt, D., \& Brand, C. (2013). Strategies for improving patient safety culture in hospitals: A systematic review. BMJ Qual Saf, 22(1), 1118. http://doi.org/10.1136/bmjqs-2011-000582

Mosadeghrad, A. M. (2013). Healthcare service quality: Towards a broad definition. International Journal of Health Care Quality Assurance, 26(3), 203-219. http://dx.doi.org/10.1108/09526861311311409

Munechika, M., Sano, M., Jin, H., \& Kajihara, C. (2014). Quality management system for healthcare and its effectiveness. Total Quality Management, 25(8), 889-896. http://doi.org/10.1080/14783363.2014.906112

New, P. W., McDougall, K. E., \& Scroggie, C. P. (2016). Improving discharge planning communication between hospitals and patients. Internal Medicine Journal, 46(1), 57-62. http://doi.org/10.1111/imj.12919

Parnaby, J., \& Towill, D. R. (2008). Enabling innovation in healthcare delivery. Health Services Management Research, 21(3), 141-154. http://doi.org/10.1258/hsmr.2007.007014

Paruch, J. L., Ko, C. Y. \& Bilimoria, K. Y. (2014). A case for improving measurement of intraoperative iatrogenic injuries. Journal of the American Medical Association Surgery, 149(9), 887-888. http://doi.org/10.1001/jamasurg.2013.5237

Pascucci, L., \& Meyer, V., Jr. (2013). Estratégia em contextos complexos e pluralísticos. Revista de Administração Contemporânea, 17(5), 536-555. Recuperado de http://www.scielo.br/pdf/rac/v17n5/v17n5a04.pdf. $\quad$ http://doi.org/10.1590/S141565552013000500003

Pina, E., Ferreira, E., Marques, A., \& Matos, B. (2010). Infecções associadas aos cuidados de saúde e segurança do doente. Revista Portuguesa de Saúde Pública, 10(1), 27-39.

Plasse, M. J. (2017, March). Authentic leadership impact on psychological safety and relationship quality in the acute care healthcare setting. Creating Healthy Work Environments, Indianapolis, Indiana, EUA. 
Podsakoff, P. M., MacKenzie, S. B., Moorman, R. H., \& Fetter, R. (1990). Transformational leader behaviors and their effects on followers' trust in leader, satisfaction, and organizational citizenship behaviors. Leadership Quarterly, 1(2), 107-142. https://doi.org/10.1016/1048-9843(90)90009-7

Price, L. et al. (2016). Toward improving the World Health Organization fifth moment for hand hygiene in the prevention of cross-infection. American Journal of Infection Control, 44(6), 631-635. http://doi.org/10.1016/j.ajic.2015.12.017

Ponsignon, F., Smart, A., Williams, M., \& Hall, J. (2015). Healthcare experience quality: An empirical exploration using content analysis techniques. Journal of Service Management, 26(3), 460-485. https://doi.org/10.1108/JOSM-10-2014-0265

Quaglini, S. (2010). Information and communication technology for process management in healthcare: A contribution to change the culture of blame. Journal of Software Maintenance and Evolution: Research and Practice, 22(6/7), 435-448. https://doi.org/10.1002/smr.461

Rafter, N. et al. (2015). Adverse events in healthcare: Learning from mistakes. Quality Journal of Medicine, 108(4), 273-277. https://doi.org/10.1093/qjmed/hcu145

Rahmqvist, M., Samuelsson, A., Bastami, S., \& Rutberg, H. (2016). Direct health care costs and length of hospital stay related to health care-acquired infections in adult patients based on point prevalence measurements. American Journal of Infection Control, 44(5), 500-506. https://doi.org/10.1016/j.ajic.2016.01.035

Rhodes, K. V. (2013). Completing the play or dropping the ball? The case for comprehensive patientcentered discharge planning. JAMA Internal Medicine, 173(18), 1723-1724. https://doi.org/10.1001/jamainternmed.2013.7854

Ribeiro, A. (2017, March). Gestão operacional. In A. Ribeiro (Ed.), Revista Observatório Anahp, (9), 82-93. Retrieved from https://ondemand.anahp.com.br/curso/publicacao-observatorio-2017edicao-09

Schmidt, R., Geisler, S., \& Spreckelsen, C. (2013). Decision support for hospital bed management using adaptable individual length of stay estimations and shared resources. BMC Medical Informatics and Decision Making, 13(3). https://doi.org/10.1186/1472-6947-13-3

Sickbert-Bennett, E. E. DiBiase, L. M., Willis, T. M., Wolak, E. S., Weber, D. J., Rutala, W. A. (2016). Reduction of healthcare-associated infections by exceeding high compliance with hand hygiene practices. Emerging infectious diseases, 22(9), 1628. https://doi.org/10.3201/eid2209.151440

Smith, C. D., Spackman, T., Brommer, K., Stewart, M. W., Vizzini, M., Frye, J., \& Rupp, W. C. (2013). Re-engineering the operating room using variability methodology to improve health care value. Journal of the American College of Surgeons, 216(4), 559-568. https://doi.org/10.1016/j.jamcollsurg.2012.12.046

$\mathrm{Su}, \mathrm{G}$. A. (2016). A collaborative approach to reduce healthcare-associated infections. British Journal of Nursing, 25(11), 582-586. https://doi.org/10.12968/bjon.2016.25.11.582

Taylor, C. (2014). The use of clinical practice guidelines in determining standard of care. Journal of Legal Medicine, 35(2), 273-290. http://doi.org/10.1080/01947648.2014.913460

Tibbs, S. M., \& Moss, J. (2014). Promoting teamwork and surgical optimization: Combining teamstepps with a specialty team protocol. Association of Operating Room Nurse Journal, 100(5), 477-488. http://doi.org/10.1016/j.aorn.2014.01.028

Titler, M. G., Jensen, G. A., Dochterman, J. M., Xie, X.-J., Kanak, M., Reed, D., Shever, L. L. (2008). Cost of hospital care for older adults with heart failure: Medical, pharmaceutical, and nursing 
costs. Health Services Research Journal, 43(2), 635-655. http://doi.org/10.1111/j.14756773.2007.00789.x

Tucker, A. L. (2004). The impact of operational failures on hospital nurses and their patients. Journal of Operations Management, 22(2), 151-169. https://doi.org/10.1016/j.jom.2003.12.006

Tucker, A. L. (2007). An empirical study of system improvement by frontline employees in hospital units. Manufacturing \& Service Operations Management, 9(4), 492-505.

Ullström, S., Sachs, M. A., Hansson, J., Øvretveit, J., \& Brommels, M. (2014). Suffering in silence: A qualitative study of second victims of adverse events. BMJ Quality \& Safety, 23(4), 325-331. http://doi.org/10.1136/bmjqs-2013-002035

Vincent, C. (2009). Segurança do paciente: Orientações para evitar eventos adversos. São Caetano do Sul: Yendis Editora.

Vogus, T. J., \& Sutcliffe, K. M. (2007). The impact of safety organizing, trusted leadership, and care pathways on reported medication errors in hospital nursing units. Medical Care, 45(10), 9971002. http://doi.org/10.1097/MLR.0b013e318053674f

Wang, X., Birch, S., Zhu, W., Ma, H., Embrett, M., Meng, Q. (2016). Coordination of care in the Chinese health systems: A gap analysis of service delivery from a provider perspective. International Journal of Integrated Care, 16(1). http://doi.org/10.1186/s12913-016-1813-8

Weller, J., Boyd, M., \& Cumin, D. (2014). Teams, tribes and patient safety: Overcoming barriers to effective teamwork in healthcare. Postgrad Medical Journal, 90(1061), 149-154. http://doi.org/10.1136/postgradmedj-2012-131168

World Health Organization. (2009). WHO guidelines on hand hygiene in health care: First global patient safety challenge. Retrieved from http://apps.who.int/iris/bitstream /10665/44102/1/9789241597906_eng.pdf

Wright, K. (2013). The role of nurses in medicine administration errors. Nursing Standard: Official Newspaper of the Royal College of Nursing, 27(44), 35-40. http://doi.org/10.7748/ns2013.07.27.44.35.e7468

Yee, R. W., Guo, Y., \& Yeung, A. C. (2015). Being close or being happy? The relative impact of work relationship and job satisfaction on service quality. International Journal of Production Economics, 169, 391-400. https://doi.org/10.1016/j.ijpe.2015.08.021

Yin, R. K. (2015). Estudo de caso: Planejamento e métodos. Porto Alegre: Bookman editor.

Yoon, J., Kim, M., \& Shin, J. (2016). Trust in delegation and leadership of registered nurses in longterm-care hospitals. Journal of Nursing Management, 24(5), 676-685. http://doi.org/ 10.1111/jonm. 12372

Zhang, R., Fry, M. J., \& Krishnan, H. (2015). Efficiency and equity in healthcare: An analysis of resource allocation decisions in a long-term home care setting. INFOR: Information Systems and Operational Research, 53(3), 97-112. http://doi.org/10.3138/infor.53.3.97

Zu, X., \& Kaynak, H. (2012). An agency theory perspective on supply chain quality management. International Journal of Operations \& Production Management, 32(4), 423-446. https://doi.org/10.1108/01443571211223086 


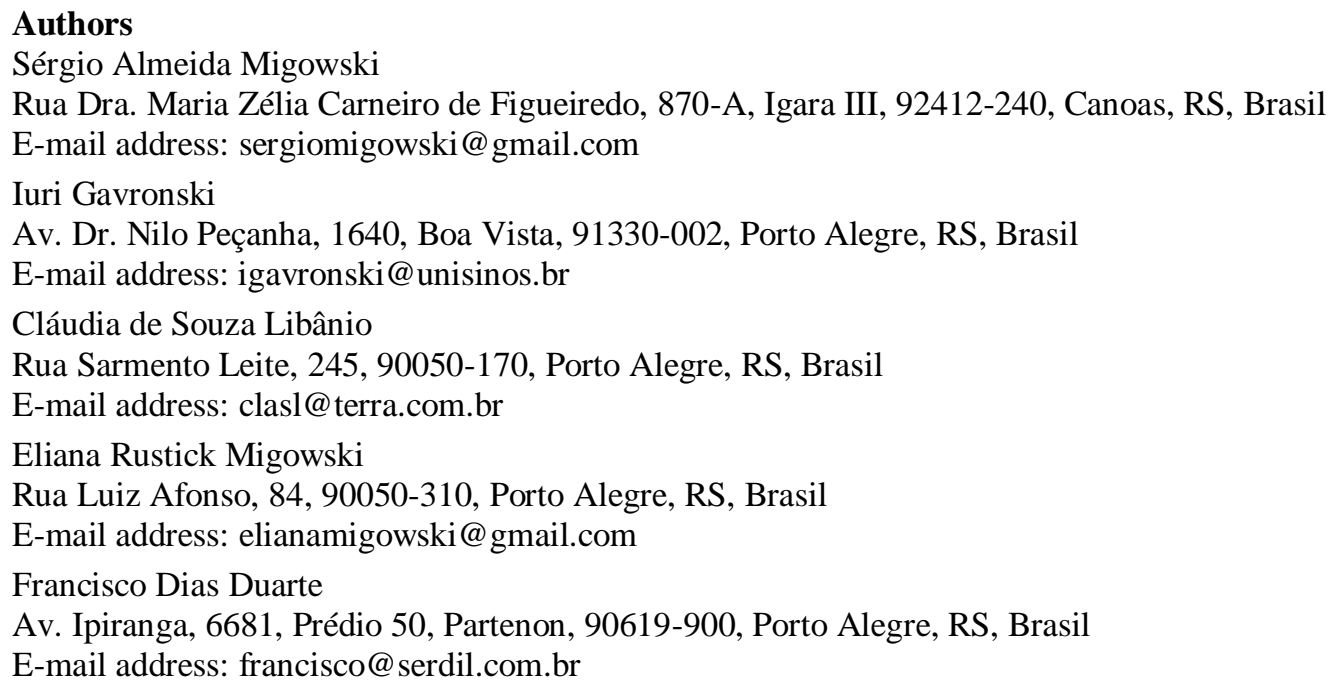

\section{Contributions}

1st author: article derived from his doctoral thesis, defended in the Graduate Program in Administration.

2nd author: supervisor of the 1st author; helped in all the work, from the dissertation, until in its transformation to article.

3rd author: improvements and adaptations throughout the work (introduction, theoretical increase, etc.) for the publication in the magazine, as well as turned the thesis into an article.

4th author: improvements and adaptations throughout the work (introduction, theoretical increase, etc.) for the publication in the magazine, as well as turned the thesis into an article.

5th author: assisted in the validation of the interviews through analysis of the data to confront the results found by the 1 st author.

\section{Funding}

This study was financed in part by the Coordenação de Aperfeiçoamento de Pessoal de Nível Superior - Brasil (CAPES - Processo: POS-DOC 88881.120322/2016-01). The first two authors were fellows during their doctorate and the postdoctoral respectively.

\section{Conflict of Interest}

The authors declare they have no competing interests.

\section{Plagiarism Check}

The RAC maintains the practice of submitting all documents approved for publication to the plagiarism check, using specific tools, e.g.: iThenticate. 